\title{
MASS TRANSPORT MODEL THROUGH THE SKIN BY MICROENCAPSULATION SYSTEM
}

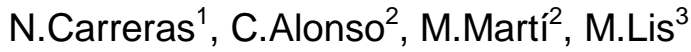 \\ (1)Polytechnic University of Catalonia - Department of Chemical Engineering, Colom \\ 1, 08222 Terrassa, Barcelona, Spain. \\ (2)Institut de Química Avançada de Catalunya, (IQAC-CSIC), Jordi Girona 18-1, 08034 \\ Barcelona, Spain \\ (3)INTEXTER-UPC. Polquitex Research Group. Colom, 15, 08222 Terrassa, \\ Barcelona, Spain
}

\begin{abstract}
Skin drug delivery can be subdivided into topical and transdermal. In a topical administration, the drug is intended to act at skin level, this is indicated for the treatment of skin diseases such as follicle-related disorders (for example, acne and alopecias). Ihe aim of transdermal administration is getting a systemic release, and in this case the skin represents a barrier and not a target. Transdermal administration can take advantage of chemical and physical strategies that can improve skin permeability and can allow to drug penetration.
\end{abstract}

In this study the development of the skin penetration profile have carried out by in vitro technique for a microencapsulated system of Ibuprofen and was determined using pig skin. The release experiments are performed using absorption percutaneous test with Franz cells apparatus in order to know the evolution of the amount of the principle present in each of the different skin compartments (stratum corneum, epidermis and dermis) as well as in the receptor fluid, as a function of time by HPLC analysis. It has achieved a general kinetic model by a microencapsulated system as mass transport system through the skin.

This modelization could serve to predict penetration in human skin of encapsulated substances from biofunctional textiles and the estimation of the dosification profile of the active principle.

Keywords: Microencapsulation, biofunctional textile substrates, in vitro skin delivery, ibuprofen.

\section{INTRODUCTION}

The transdermal drug release is a viable administration route for powerful, lowmolecular weight therapeutic agents, which has to be precise in their control of drug distribution. This strategy is specially recommended for many drugs that are difficult to 
be taken since they must be delivered slowly over a prolonged period to have a beneficial effect. However, there is still necessary to research in this field. For instance, the drug release modelling of biodegradable polymeric systems by encapsulation technology in textiles has not progressed much yet, due to its high complexity.

The topical administration shows far less problems than the transdermal one for the use of drug delivery system. However, transdermal administration has several interesting advantages over other systemic administration routes such as:

a) The reduction of first-pass drug degradation as the liver is initially bypassed.

b) The reduction of over dosage peaks that can appear in oral administration.

c) The existence of variable delivery conditions, typical of the gastrointestinal tract.

Transdermal administration also can take advantage of chemical and physical strategies that can improve skin permeability and allow to drug penetration [1-8]. Specifically, the transdermal drug delivery is a good viable administration route for powerful, low-molecular weight therapeutic agents which either can or cannot withstand the hostile environment of the gastrointestinal tract are subject to considerable firstpass metabolism by the liver [9]. Regardless of the necessity or not of physicalchemical enhancing, for a reliable and effective designing of transdermal delivery systems it is fundamental prerequisite the knowledge of skin structure and its properties [2].

The human skin is composed of three layers, consisting in: Stratum Corneum, Epidermis and Dermis (Figure 1), the outer layer is the Stratum Corneum. Epidermis is put in contact with the dermis by the so-called dermo-epidermic junction (as permeable area). The dermis is constituted by a connective tissue layer of mesenchymal origin. Finally, the inner layer is represented by the hypodermis, mainly constituted by connective tissue.

For that reason, the drug release to the skin surface and its transport to the systemic circulation are studied as a multistep process which involves:

a) dissolution within and release from the drug formulation,

b) partitioning into the skin's outermost layer, the Stratum Corneum (SC),

c) diffusion through the SC, principally via a lipidic intercellular pathway, (i.e., the rate-limiting step for most compounds),

d) partitioning from the SC into the aqueous viable epidermis,

e) diffusion through the viable epidermis and into the upper dermis, and

f) uptake into the local capillary network and eventually the systemic circulation (Figure 1). 


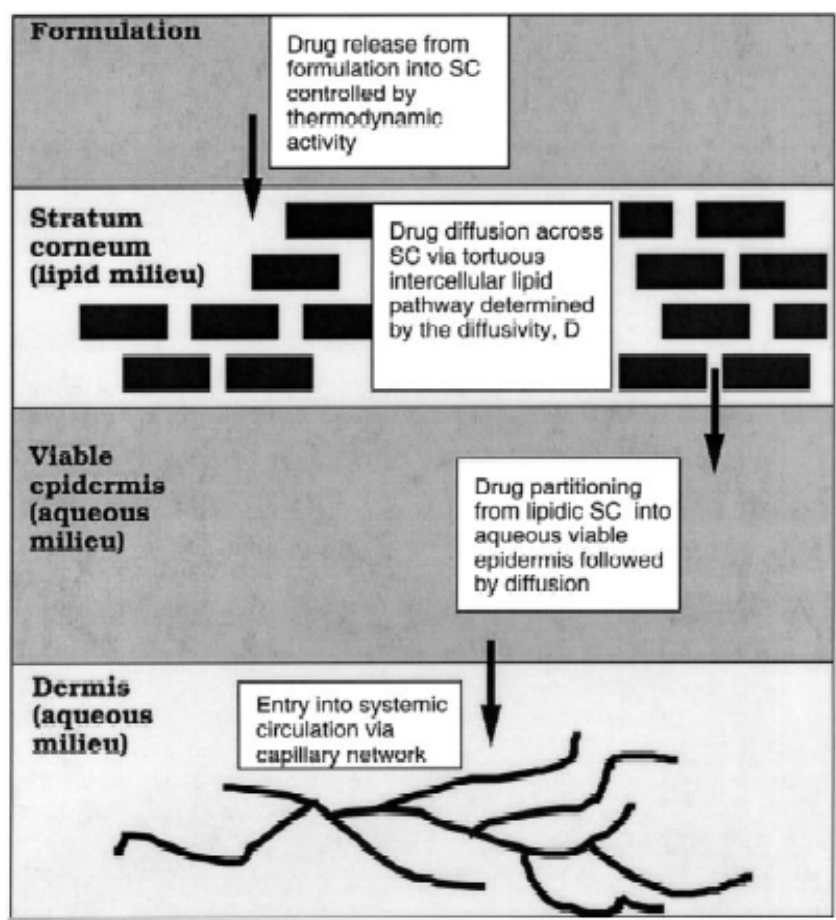

Figure 1. Schematic representation of the transport processes involved in drug release from the formulation up to its uptake through the dermal capillaries. [9]

Therefore, an ideal drug candidate would have sufficient lipophilicity to partition into the SC, but also sufficient hydrophilicity to enable the second partitioning step into the viable epidermis and eventually the systemic circulation.

A transdermal drug release is a formulation or device (for example, a transdermal patch) that maintains the blood concentration of the drug for therapeutic purposes. It should ensure that drug levels neither fall below the minimum effective concentration nor exceed the minimum toxic dose [9].

It is important to advance in these fields, because it is necessary the availability of alternative methods to human experimentation. In vitro methods, using human or animal skin, can serve the purpose. However, sometimes without a reliable in vivo animal model, definitive conclusions are difficult to be obtained. Thus, animal models have been widely considered.

The pig model is one of most important of particular interest. The common anatomical and physiological characteristics between man and pig indicate that the pig represents a reliable model to study percutaneous permeation in man. Pig skin is a representative membrane for percutaneous absorption because it has permeation characteristics similar to those of human skin [10]. The density of hair follicles is similar in human and porcine skins [11]. 
Also permeation tests substantially confirm the similarities between human and pig skin. For instance, in vitro permeation of skin to water revealed that human and porcine skins were similar, as well as other compounds $[10,11]$.

Historically speaking, the first mathematical model of drug permeation phenomenon through skin is the one proposed by Higuchi. Then, many other authors developed excellent research studies on this topic, finding several models based on the changes on active principle concentrations.

These models can be divided into two main groups: empirical and mechanistic models. Mechanistic models are divided into two categories: Analysis based on simple diffusion models (Fick's diffusion law, Quantitative structure-activity relationship (QSAR) methods) and Analysis based on heterogeneous diffusion models. Empirical analysis of skin permeation of drugs is based on molecular structures such as a Neural network modelling to predict of skin permeability [18-24].

Guy and Hadgraft $[9,14]$ developed a mathematical model in order to investigate the effect of the variation of thickness during drug release through the skin. Accordingly, the experimental permeation data are fitted by the following equation, suitable to describe drug permeation through a thin membrane:

$$
\frac{M_{\mathrm{t}}}{M_{\infty}}=\left(1-\exp \left(-\frac{D_{\mathrm{s}} t}{K L_{\mathrm{o}} L_{\mathrm{s}}}\right)\right)
$$

where $M_{t}$ is the total amount of drug that passes through the layers of skin, $L_{s}$ is stratum corneum thickness and $L_{0}$ the formulation thickness, during period $t . D_{s}$ is the diffusion coefficient of the drug through the different skin layers and $K$ is a partition coefficient between skin layer and drug formulation (typically $\mathrm{K}=$ concentration in skin layer/concentration in vehicle).

In this work, skin delivery of ibuprofen embedded into biofunctional textiles was studied by a specific in vitro percutaneous absorption methodology. Percutaneous absorption is an interdisciplinary subject that is relevant to a number of widely fields [31]. The main areas of interest are the development of transdermal devices, dermatological formulations and safety assessment of cosmetic topically applied.

Encapsulation is one of the techniques used to apply the substances to textiles [32]. Biodegradable polymer micro or nanoparticles are of great interest as drug delivery systems because their ability to be reabsorbed by the body. Synthetic aliphatic linear

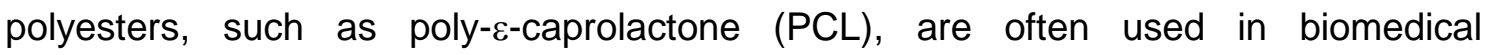
applications [32] because they are biocompatible, non-toxic and have certain 
advantages compared to other polymers such as PLA (poly lactic acid): (a) it is more stable in ambient conditions; (b) it is significantly less expensive and, (c) it is readily available in large quantities [33].

The mechanism of drug release is often dominated by drug diffusion from microsphere matrix, which makes PCL-microespheres suitable for long term drug release system [34]. $\mathrm{PCL}$ is a semi-crystalline polymer having glass transition temperature $-60^{\circ} \mathrm{C}$ and melting point ranging between 59 and $64^{\circ} \mathrm{C}$, depending upon its crystalline nature. PCL is soluble in chloroform, dichloromethane, carbon tetrachloride, benzene, toluene, cyclohexanone and 2-nitrochloride at room temperature [34].

Generally the active principle is dissolved, entrapped, encapsulated or attached to the polymeric microoparticles, depending on the method of preparation, namely emulsification-evaporation, emulsification-diffusion and solvent displacement. In this work, a w/o/w double emulsion solvent extraction/evaporation method was used.

As textile substrat, cotton was used. Cotton (CO) is the natural fibre most commonly used for human with skin disease such as contact dermatitis. CO has inherent properties like good folding endurance, better conduction of heat, easy dyeability and excellent moisture absorption [35].

\section{MATERIALS AND METHODS}

\subsection{Chemicals}

Microspheres $(6,25 \%$ ibuprofen $93,75 \%$ water) were prepared by the solvent evaporation method, forming microemulsions ( $\mathrm{w}_{1} / \mathrm{o} / \mathrm{w}_{2}$ double emulsion) with a shield of PVA and PCL for an external wall. These were applied on a foulard onto a textile substrate. In this work, standard woven fabric was used, Cotton fabric (COT) (Style, ISO 105 - F02). All chemicals used were of analytical grade.

In this case, $0.26 \%$ Gallic Acid (GA) was dispersed in water and added to other solution of $0.26 \%$ polymer $P C L$ in dichloromethane. The simple emulsion $\left(w_{1} / 0\right)$ was generated by mechanical agitation (UTRA-TURRAX T25, IKA) for several minutes at $24000 \mathrm{rpm}$. Afterwards, this simple emulsion was added to a continuous phase, constituted of $150 \mathrm{ml}$ aqueous solution of PVA (1.78\%) and emulsified for several minutes at $24000 \mathrm{rpm}$, resulting in a double emulsion $\left(\mathrm{w}_{1} / \mathrm{o} / \mathrm{w}_{2}\right)$. The mixture was maintained under agitation at $400 \mathrm{rpm}$ (20h) leading to the solvent evaporation and consequently the microsphere formation. The method used was carried out at $4^{\circ} \mathrm{C}$. 
The application of microcapsules onto the fabrics was carried out by the foulard process using a Pad-Dry technique of $30 \mathrm{~cm}$ width (ERNST BENZ AG KLDHT and $\mathrm{KTF} / \mathrm{m} 250$ ) and followed by a process of drying at room temperature, with the padding pressure to obtain a pick-up of $80 \pm 5 \%$, from the microencapsulation formulations. The treated fabric samples were finally conditioned at $20 \pm 2^{\circ} \mathrm{C}$ and $65 \pm 5 \%$ relative humidity for $24 \mathrm{~h}$ before weighing and proceeding to perform subsequent experiments.

\subsection{Percutaneous Absorption assay}

The percutaneous absorption essay is based on in vitro technique using an experimental apparatus (Franz Cell) aimed to measure skin permeability. The study has been carried out for ibuprofen system (applied on cotton fabric), since there is no literature for this type of study, and it is of great interest to achieve improvements in the biotechnology field.

The experimental apparatus (Franz Cell) was proposed in mid-1970s by Franz. Simply, Franz Cell is a double-walled beaker characterized by a top donor chamber separated from the receiver chamber by skin. While thermostatic fluid flows inside the beaker double wall, receiver sampling takes place from the sampling port. Skin permeability is evaluated on the basis of drug concentration increase in the receiver environment. In vivo tests are usually conducted on human, rodent, and pig skin, which is the best approximation of human skin. Sometimes monkey skin is also used [2,14-18].

Complex situations may happen in the drug release. They can be summarized in four simple conditions concerning release properties of the formulation:

a) Formulation can match drug dissolution.

b) Formulation can show drug dispersion in a liquid phase [19].

c) A polymeric matrix containing the drug in a dissolved or an undissolved form.

d) Drug solution reservoir separated from the skin by a matrix.

The in vitro studies is carried out with pig skin on Franz static diffusion cells in order to know the evolution of the amount of the principle present in each of the different skin compartments (SC, epidermis and dermis) as well as in the receptor fluid, as a function of time by HPLC analysis.

\subsubsection{HPLC analysis}

HPLC analysis of ibuprofen was performed using a Hitachi-Merck equipment (L-4250 UV-vis detector, L-6200 Intelligent Pump, AS-4000 Intelligent Autosampler and a D- 
6000 Interfase). A LiChrocart 250-4/LiChrosorb RP-18 (5 $\mu \mathrm{m})$ column was used to quantify the five compound.

Elution conditions for detection of ibuprofen were as follow: eluent A: phosphoric acid (1.2\%)( Merck, Darmstadt, Germany), eluent B: methanol (Merck, Darmstadt, Germany) at isocratic conditions $(33 \% \mathrm{~A})$ at $14 \mathrm{~nm}$. The flow for the detection of the compound was $1 \mathrm{~mL} / \mathrm{min}$ and $40 \mu \mathrm{L}$ of injection volume. Calibration curve used for the assessment of the concentration of ibuprofen was $y=10856 x+1096\left(r^{2}=0,999\right)$.

\subsubsection{Percutaneous absorption}

The skin penetration profile for ibuprofen determined using pig skin. The OECD Guidelines and the opinion of the Scientific Committee on Cosmetic Products and NonFood Products (SCCNFP) were closely adhered to during this study (1-3). Also, some other classical and update principles of percutaneous absorption were considered (4, $5)$.

The porcine skin used in this study was obtained from the unboiled back of domestic pigs (Landrace Large White race) The treated and dermatomed pigskin discs were supplied by a research group (Biophysics of Lipids and Interphases group) of IQACCSIC.. Most of subcutaneous fat was eliminated with a scapel and the skin was rinsed with tap water. The bristles were cut with a special electric clipper for animals. The skin was then dermatomed to a thickness of $500 \mu \mathrm{m} \pm 50 \mu \mathrm{m}$ (Dermatome GA630, Aesculap, Germany). A punch was used to obtain skin discs (2.5 cm inner diameter) which fit into the penetration cells. Skin discs were frozen at $-20^{\circ} \mathrm{C}$ and thawed at room temperature immediately prior to processing.

The penetration cells ( $3 \mathrm{~mL}, 1.86 \mathrm{~cm}^{2}$, Lara-Spiral, Courtenon, France) consisted of the upper donor and the lower receptor chamber, separated by a skin biopsy. Before positioning the skin on the lower part of the cell, with the stratum corneum facing the donor chamber, a magnetic stirring bar was introduced. The lower part was filled with a receptor fluid through the lateral inlet of the cell using a Pasteur pipette $(\sim 3 \mathrm{~mL})$. The receptor fluid was phosphate-buffered saline at $\mathrm{pH} 7.4$ (Sigma, St Louis MO, USA) in distilled water (containing $0.9 \% \mathrm{NaCl}, 0.02 \% \mathrm{KCl}$ and $0.8 \%$ phosphate buffer).

The penetration cells were placed in a thermostated water bath (Telesystem HP 15, $\mathrm{H}+\mathrm{P}$ Labortechnik $\mathrm{GmbH}$, Germany) in order to ensure that the skin surface temperature was maintained at $32^{\circ} \mathrm{C}$ and a magnetic stirring (Variomag 15and Telemodul , H+P Laortechnik $\mathrm{GmbH}$, Germany). Integrity of the skin samples was evaluated measuring the transepidermal water loss (TEWL) with a Tewameter TM210 (Courage \& Khazaka, Cologne, Germany). A minimum of 6 diffusion cells are required for each experimental assay. $6 \mathrm{~cm}^{2}$ of textile containing ibuprofen was applied to the entire surface of each diffusion cell and remained fixed with the upper cell. A cylindrical 
weight was placed on the surface of the textile during all the exposure time to assure a good contact between the textile and the skin simulating the contact of the clothes with the human skin in conditions standard. One control cell applied with placebo textile was also used. At the end of the period of exposure $(1,3,6,24$ and $37 \mathrm{~h})$, the textile was remove from skin surface. Then, the receptor fluid was recovered into a $5 \mathrm{~mL}$ volumetric flask. The surface horny layers of stratum corneum were removed using an adhesive tape (D-Squame, Cuderm Corporation, Dallas, USA) applied under controlled pressure $\left(80 \mathrm{~g} / \mathrm{cm}^{2}\right.$ for few seconds). The epidermis was separated from the dermis after heating the skin at $80^{\circ} \mathrm{C}$ for a few seconds. The dermis was cut into small pieces with a scalpel.

The different samples to be analyzed were extracted and/or diluted in methanol (Darmstadt, Germany) as follows: the receptor fluids were injected directly, each textile applied was diluted with $10 \mathrm{~mL}$ of solvent, tapes samples were put in $2 \mathrm{~mL}$ whereas viable epidermis and dermis samples were put in $1 \mathrm{~mL}$. After one night of contact in the solvent, all samples were stirred during $30 \mathrm{~min}$ at room temperature and the dermis, epidermis and stratum corneum samples were sonicated for $15 \mathrm{~min}$.

After filtration on Nylon filter $(0.45 \mu \mathrm{m}$, Cameo N, Scharlab, Spain), solutions were assessed by HPLC.

From the concentrations of ibuprofen in each layer of the porc skin, and trough the linearization of eq. (1), apparent diffusion coefficients have been calculated.

\section{RESULTS AND DISCUSSION}

Mass transport model through the skin was determined from the kinetic study of skin layers. For this study, the percutaneous absorption essay was carried out repeatedly (3 repetitions) for several samples of treated cotton with ibuprofen PCL-microspheres at different times (see Table 1).

The results of ibuprofen diffusion for PCL-microspheres system applied on cotton fabric are expressed as $\mu \mathrm{g} / \mathrm{cm}^{2}$, at different times. They are indicated in Table 1. 
Table 1. The amount of drug released in each part of the skin versus time. Exposure times: from 0 to $37 \mathrm{~h}$. Values represent mean \pm S.D $(n=3)$.

\begin{tabular}{|c|c|c|c|c|c|c|c|}
\hline $\begin{array}{c}\text { TIME } \\
\text { (h) }\end{array}$ & $\begin{array}{c}\text { Tex* }^{*} \\
\left(\mu \mathrm{g} / \mathrm{cm}^{2}\right)\end{array}$ & $\begin{array}{c}S C^{*} \\
\left(\mu \mathrm{g} / \mathrm{cm}^{2}\right)\end{array}$ & $\begin{array}{c}E^{*} \\
\left(\mu \mathrm{g} / \mathrm{cm}^{2}\right)\end{array}$ & $\begin{array}{c}D^{*} \\
\left(\mu \mathrm{g} / \mathrm{cm}^{2}\right)\end{array}$ & $\begin{array}{c}S^{*} \\
\left(\mu \mathrm{g} / \mathrm{cm}^{2}\right)\end{array}$ & $\begin{array}{c}\mathrm{RF}^{*} \\
\left(\mu \mathrm{g} / \mathrm{cm}^{2}\right)\end{array}$ & $\begin{array}{c}\text { Total } \\
\left(\mu \mathrm{g} / \mathrm{cm}^{2}\right)\end{array}$ \\
\hline 0 & $15.07 \pm 3.94$ & $n d^{\star \star}$ & $n d^{\star *}$ & $n d^{\star *}$ & $\mathrm{nd}^{\star \star}$ & $n d^{\star \star}$ & $15.07 \pm 3.94$ \\
\hline 1 & $9.08 \pm 0.36$ & $\begin{array}{c}1.34 \\
\pm 0.52\end{array}$ & $\begin{array}{c}0.32 \\
\pm 0.10\end{array}$ & 0 & $\begin{array}{c}1.70 \\
\pm 0.87\end{array}$ & 0 & $12.44 \pm 0.48$ \\
\hline 3 & $8.97 \pm 0.78$ & $\begin{array}{c}1.62 \\
\pm 0.22\end{array}$ & $\begin{array}{c}0.91 \\
\pm 0.38\end{array}$ & $\begin{array}{c}0.94 \\
\pm 0.12\end{array}$ & $\begin{array}{r}2.40 \\
\pm 2.05\end{array}$ & 0 & $14.84 \pm 1.21$ \\
\hline 6 & $9.59 \pm 0.35$ & $\begin{array}{r}2.45 \\
\pm 0.31\end{array}$ & $\begin{array}{c}1.79 \\
\pm 0.14\end{array}$ & $\begin{array}{c}1.53 \\
\pm 0.29\end{array}$ & $\begin{array}{c}0.97 \\
\pm 0.22\end{array}$ & 0 & $16.32 \pm 2.47$ \\
\hline 24 & $8.36 \pm 1.90$ & $\begin{array}{c}2.94 \\
\pm 0.46\end{array}$ & $\begin{array}{c}2.89 \\
\pm 0.09\end{array}$ & $\begin{array}{c}1.55 \\
\pm 0.15\end{array}$ & $\begin{array}{c}2.15 \\
\pm 0.87\end{array}$ & $\begin{array}{c}0.64 \\
\pm 0.65\end{array}$ & $17.88 \pm 2.31$ \\
\hline 37 & $8.10 \pm 0.52$ & $\begin{array}{c}1.07 \\
\pm 0.42\end{array}$ & $\begin{array}{c}0.58 \\
\pm 0.15\end{array}$ & $\begin{array}{c}1.26 \\
\pm 0.45\end{array}$ & $\begin{array}{c}3.35 \\
\pm 0.16\end{array}$ & $\begin{array}{c}5.11 \\
\pm 0.86\end{array}$ & $19.47 \pm 0.58$ \\
\hline
\end{tabular}

*Abbreviations: Tex: Textile; SC: Stratum Corneum; E: Epidermis; D: Dermis; S: Surplus; RF: Receptor fluid; **nd: not detected

The kinetic evolution of ibuprofen penetrated in each skin layer is shown in Figure 2. As it can be seen, the kinetic study shows that ibuprofen has penetrated through every layer of the skin; even it reaches the receptor fluid for a time longer than 24 hours.

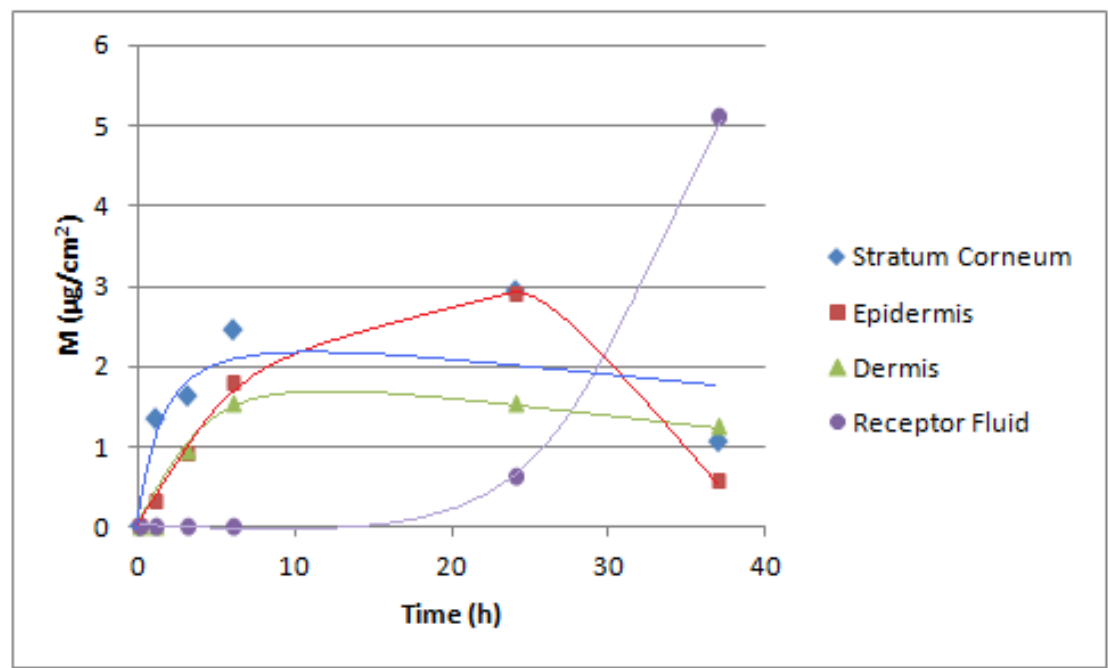

Figure 2. Kinetic release of PCL-microspheres with ibuprofen applied on to cotton fabric through the skin layers.

From the results obtained, it can be seen that at early times, the ibuprofen delivery to Stratum Corneum increases up to 6 hours approximately and then, it gradually decreases over time. But, this is a normal tendency, since in the second layer of skin (epidermis), the release of ibuprofen is slower. However, taking the same time (6 hours) the amount of ibuprofen released increases more in this layer than in the dermis. This fact could be due to a saturation of the ibuprofen between the two first layers of the skin. Therefore, the close contact with the skin and the occlusion of the 
skin could be the main reasons for the active compound can cross the skin barrier located in the stratum corneum [23]. For this reason, in 24 hours, the release of ibuprofen has increased in the epidermis, but instead, has decreased in the stratum corneum and in the dermis. In contrast, in the receptor fluid is when it begins to increase. Therefore, one can observe that there is an equilibrium between one layer and another, up to 37 hours, when the ibuprofen release decreases in the epidermis and therefore, there is a considerable increase of ibuprofen release in the receptor fluid. It should also be taken into account the amount of hours for the study, as the degradation of the system can increase, either PCL-microspheres or the experimental devices itself, in this case the pigskin.

The model developed by Guy and Hadgraft has been used with the aim of investigating the ibuprofen released through the skin. In the equation (1), the relationship between the diffusion coefficient of the drug through the different skin layers $\left(D_{s}\right)$ and the formulation thickness during a given period $t\left(L_{0}\right)$, is considered the apparent diffusion coefficient.

When $D_{a p}=\frac{D_{s}}{L_{0}}$, the equation (1) is transformed in the following expression (2):

$$
\frac{M_{t}}{M_{\infty}}=\left(1-\exp \left(-D_{a p} \frac{t}{K L}\right)\right)
$$

This has been used in our work taken into account the experimental parameters obtained for each skin layer. As regards to the partition coefficient $(\mathrm{K})$ of ibuprofen, Herkenne et al [26] determined that parameter in SC using propylene glycol as a solvent. The individual partition coefficients obtained as a function of ibuprofen concentration in the cosolvent are graphically plotted in Figure 3. Although the solvent used in our work has been methanol, the solubility of ibuprofen in both solvents is quite similar (ibuprofen solubility in propylenglycol: $140.00 \mathrm{mg} / \mathrm{mL}$ [27] whereas in methanol is: $144.50 \mathrm{mg} / \mathrm{mL}$ ). Therefore, as it can be deduced from the values shown in Figure 3 , the partition coefficient $(\mathrm{K})$ of ibuprofen is about 1. 


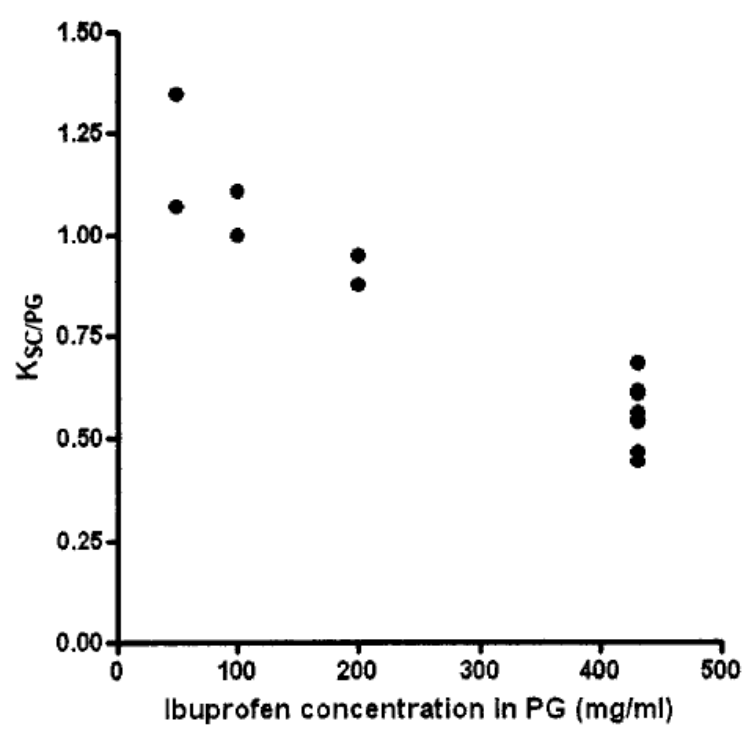

Figure 3. Individual SC/PG partition coefficients measured in vivo as a function of ibuprofen concentration in the cosolvent [26]

For the calculation of the apparent diffusion coefficients of ibuprofen, it must be considered the hydrophilic or lipophilic character of each skin compartment. The stratum corneum (SC) is a lipophilic layer whereas the epidermis and, in particular, dermis are the hydrophilic areas of the skin (viable skin). The results on apparent diffusion coefficients obtained for each layer are shown in Table 2.

Table 2. Apparent diffusion coefficients for Stratum Corneum and Epidermis-Dermis.

\begin{tabular}{ccc}
\hline LAYERS & THICKNESS $(\boldsymbol{\mu m})$ & $\mathrm{D}_{\mathrm{ap}}(\mathrm{cm} / \mathbf{s})$ \\
\hline STRATUM CORNEUM & 20 & $1.20 \cdot 10^{-1}$ \\
VIABLE SKIN & 667.3 & $6.673 \cdot 10^{-6}$ \\
\hline (EPIDERMIS-DERMIS) & & \\
\hline
\end{tabular}

It can be seen that in the lipophilic area of skin (stratum corneum), the release of the active compound is the slowest, this is due to the properties of its barrier function. The diffusion through the SC is mainly a lipidic intercellular pathway, therefore it can be considered the rate-limiting step for most compounds. However, once the active compound crosses through the epidermis and dermis (hydrophylic area of skin) the release rate increases significantly, even reaching to the receptor fluid.

As the ibuprofen penetrates into the skin, its solubility increases. According to the literature [26,28-30], the solubility of ibuprofen in a phosphate buffer solution (receptor fluid) at a temperature of $37{ }^{\circ} \mathrm{C}$ and $\mathrm{pH}=7.4$ is $6.02 \mathrm{mg} / \mathrm{mL}$. However, ibuprofen has a very low water solubility $(0.14 \mathrm{mg} / \mathrm{mL})$, and in the lipophylic layer (SC) the ibuprofen release is slower than in the hydrophilic domain (epidermis-dermis). 
PCL-microspheres can reduce the diffusivity of active compound in the first layer of the skin due to a surface skin saturation and thus, driving to a slower delivery of ibuprofen versus time. Therefore, the phenomenas observed are either the drug release fully determined by the affinity of the active compound with the different layers of the skin, or collapse on the surface of the skin together with a slower drug release.

Once ibuprofen enters to the hydrophilic part of the skin, its solubility increases, release to the receptor fluid is faster, while the solubility of the ibuprofen is very high (6.02 $\mathrm{mg} / \mathrm{mL}$ ). Moreover, in previous studies about the variation of solubility of the ibuprofen versus time [29], it is demonstrated that its solubility increases exponentially in the time. Due to the hydrophobic nature of ibuprofen, the aggregation of ibuprofen powders is obtained during the dissolution testing [29]. And, in this study, there is a good dispersion of the ibuprofen, because, basically, this takes part of a microencapsulation system, thus avoiding the aggregation of the active agent.

As a conclusion, the model of mass transport of ibuprofen through the skin used in this study is illustrated in the scheme of Figure 4. As it can be seen, an specific equation is used for each skin layer considering the percutaneous absorption kinetics of ibuprofen. This simple and practical model allows the control of a drug delivery system consisting of PCL-microspheres applied on textile substrate as a method of controlled release of ibuprofen.

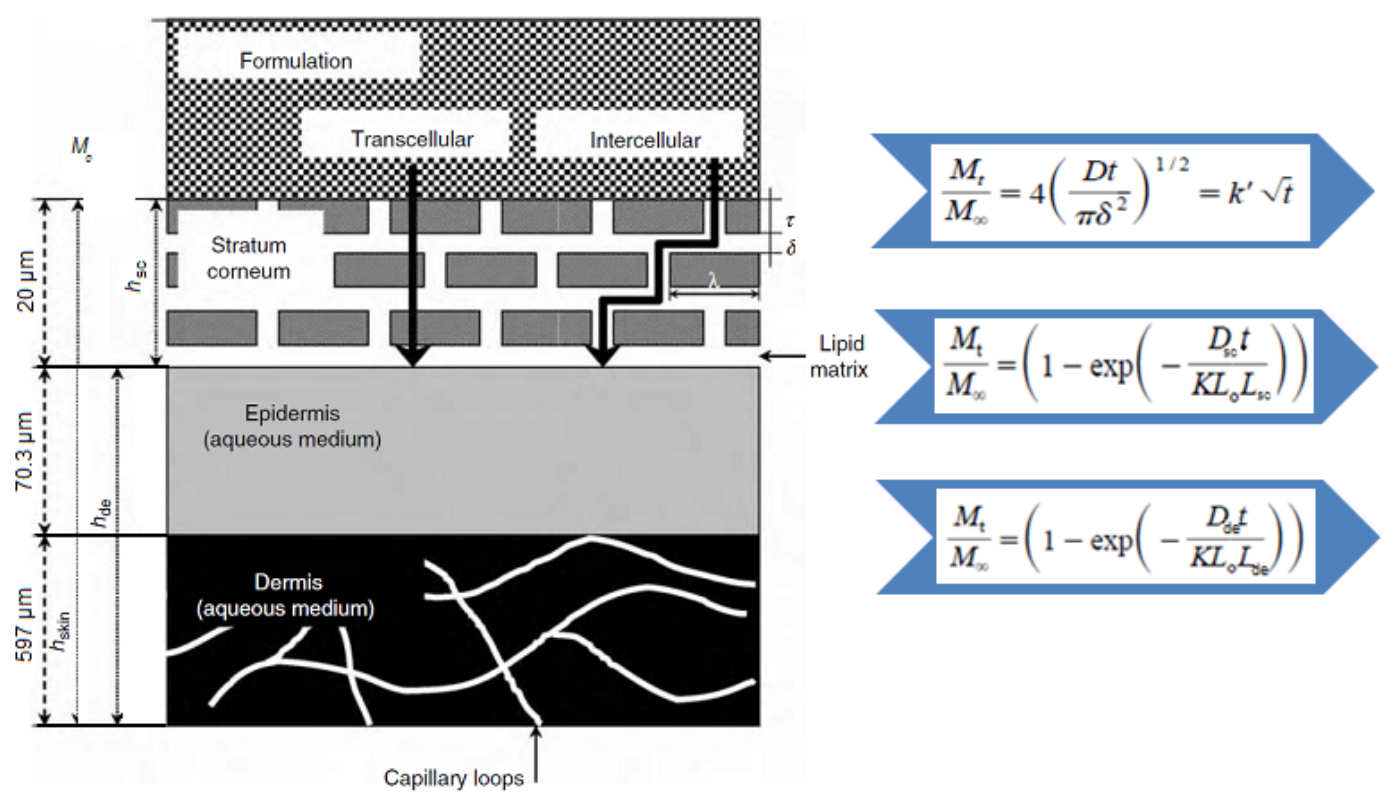

Figure 4. Model of mass transport of ibuprofen through the skin.

\section{CONCLUSIONS}

This study shows that the bioavailability of a model of ibuprofen microencapsulated in the skin can be evaluated by Franz-cells in vitro technique. This technique, combined 
with the appropriate analysis of the experimental data, provides kinetic parameters needed to design rationally a topical patch. Moreover, the role of PCL-microspheres, as a mass transport carrier in topical formulations of moderately lypophilic drugs as ibuprofen, has been examined carefully. The ibuprofen get in the SC slowly and seems to alter ibuprofen's solubility in the barrier. However, the diffusivity of the drug across the epidermis-dermis (aqueous area) increases significantly, and the drug delivery is directly affected by the solubility of active compound. Quantitative characterization of the uptake of ibuprofen itself into the different layers of the skin from PCL-microspheres represents a logical research effort for future investigations.

In this study it has been demonstrated that the microencapsulation applied on textiles is a good system of controlled drug release. As a result, the project has been completed with a general kinetic model by smart textiles as a transport system through the skin.

\section{REFERENCES}

[1] R.W. Baker, H.K. Lonsdale, Controlled release: mechanisms and rates, Controlled Release of Biologically Active Agents, Plenum Press, New York (1974) 15-72.

[2] M. Grassi, G. Grassi, R. Lapasin, I. Colombo, Understanding drug release and absorption mechanisms, Taylor and Francis Group, (2007) Chapter 9, 583-584.

[3] R.S, Harland, N.A, Peppas, On the accurate experimental determination of drug diffusion coefficients in polymers, S.T.P. Pharm. Sci., 3 (1993) 357.

[4] K. Tojo, et al., Characterization of a membrane permeation system for controlled delivery studies, AIChE J., 31 (1985) 741.

[5] N. Laghoueg, et al., Oral polymer-drug devices with a core and an erodible shell for constant drug delivery, Int. J. Pharm., 50 (1998) 133.

[6] A. Lavasanifar, et al., Microencapsulation of theophylline using ethilcellulose: in vitro drug release and kinetic modeling, J. Microencapsul., 14 (1997) 91.

[7] M.L Lorenzo-Lamosa, et al., Design of microencapsulated chitosan microspheres for colonic drug delivery, J. Contr. Rel., 52 (1998) 109.

[8] E.M. Ouriemchi, J.M. Vergnaud, Processes of drug transfer with three different polymeric systems with transdermal drug delivery, Comput. Theor. Polym. Sci., 10 (2000) 391. 
[9] Y. N. Kalia, R. H. Guy, Modeling transdermal drug release, Advanced Drug Delivery Reviews, 48 (2001) 159-172.

[10] Alonso, C.; Ramón, E.; Lozano, C.; Parra, J. L.; Torres, J. L.; Coderch, L. Percutaneous absorption of flavan-3-ol conjugates from plant procyanidins. Drugs Exp. Clin. Res. 30:1-10; 2004.

[11] Bronaugh, R. L.; Stewart, R. F.; Congdon, E. R. Methods for in vitro percutaneous absorption studies. II. Animal models for human skin. Toxicol. Appl. Pharm. 62:481488; 1982.

[12] N. He, et al., Model analysis of flux enhancement across hairless mouse skin induced by chemical permeation enhancers, Int. J. Pharm., 9 (2005) 297.

[13] T.J. Franz, Percutaneous absorption on the relevance of in vitro data, J. Invest. Dermatol., 64 (1975) 190.

[14] T.J. Franz, The finite dose technique as a valid in vitro model for the study of percutaneous absorption in man, Curr. Probl. Dermatol., 7 (1978) 58.

[15] T. Higuchi, Rate of release of medicaments from ointment bases containing drugs in suspension, J. Pharm. Sci., 50 (1961) 874.

[16] B. Illel, et al., Follicles play an important role in percutaneous absorption, J. Pharm. Sci., 80 (1991) 424.

[17] N. Coceani, I. Colombo, M. Grassi, Acyclovir permeation through rat skin: mathematical modelling and in vitro experiments, International Journal of Pharmaceutics, 254 (2003) 197-210

[18] F. Yamashita, M. Hashida, Mechanistic and empirical modeling of skin permeation of drugs, Advanced Drug Delivery Reviews, 55 (2003) 1185-1199.

[19] G.L. Flynn, S.H. Yalkowsky, T.J. Roseman, Mass transport phenomena and models: theoretical concepts, J. Pharm. Sci., 63 (1974) 479.

[20] M. Grassi, Membranes in drug delivery, in Handbook of membrane separations: chemical, pharmaceutical, and biotechnological applications, Sastre, A.M., Pabby, A.K., Rizvi, S.S.H., Eds., Marcell Dekker, (2007).

[21] M. Grassi, G. Grassi, Mathematical modelling and controlled drug delivery: matrix systems, Curr. Drug Deliv., 2 (2005) 97. 
[22] S.K. Inoue, R.B. Guenther, S.W. Hoag, Algorithm to determine diffusion and mass transfer coefficients, in Proceedings of the Conference on Advances in Controlled Delivery, 145 (1996).

[23] I. Colombo, et al., Determination of the drug diffusion coefficient in swollen hydrogel polymeric matrices by means of the inverse sectioning method, J. Contr. Rel., 47 (1997) 305.

[24] M. Grassi, et al., Effect of milling time on release kinetics from co-ground drug polymer systems, in Proceedings of the 2003 AAPS Annual Meeting and Exposition, \# M1201, Grassi, M., Magarotto, N.L., Ceschia, D., Eds., (2003).

[25] L. Rubio, C. Alonso, L. Coderch, J. L. Parra, M. Martí, J. Cebrián, J. A. Navarro, M. Lis and J. Valldeperas, Skin delivery of caffeine contained in biofunctional textiles, Textile Research Journal, (2010) 1215-1221.

[26] C. Herkenne, A. Naik, Y. N. Kalia, J. Hadgraft, R. H. Guy, Effect of propylene glycol on ibuprofen absorption into human skin in vivo, Journal of Pharmaceutical Sciences, 97 N 1 (2008) 185-197.

[27] E.I. Guisado, M.E. Gil, M.A. Camacho, A.I. Torres, Estudio de solubilidad de ibuprofeno en medio acuoso: Elaboración de una formulación líquida de uso pediátrico, 164 VI Congreso SEFIG y $3^{\text {as }}$ Jornadas de Tecnología Farmacéutica (2003) 161-164.

[28] K. A. Levis, M. E. Lane, O. I. Corrigan, Effect of buffer medium composition on the solubility and effective permeability coefficient of ibuprofen, International Journal of Pharmaceutics, 253 (2003) 49-59.

[29] M. Charoenchaitrakool, F. Dehghani, and N. R. Foster, Micronization by rapid expansion of supercritical solutions to enhance the dissolution rates of poorly watersoluble pharmaceuticals, Ind. Eng. Chem. Res., 39 (2000) 4794-4802.

[30] A. Ducret, M. Trani, and R. Lortie, Lipase-catalyzed enantioselective esterification of ibuprofen in organic solvents under controlled water activity, Enzyme and Microbial Technology, 22 (1998) 212-216.

[31]Shaefer H., Redelmeier T.E., in: Skin Barrier, Principles of Percutaneous Absorption., Switzerland: S. Karger AG, 1996.

[32]Z. Shaoabing, D. Xianmo, Y. Hua. Biodegradable poly ( $\varepsilon$-caprolactone) - poly (ethyleneglycol) block copolymers: characterization and their use as drug carriers for a controlled delivery system. Biomaterials., 2003, 24: 3563-3570. 
[33] D.W. Hutmacher, Scaffold in tissue engineering bone and cartilage, Biomaterials, 21 (2000), pp. 2529-2543

[34]V.R. Sinha,, K. Bansal, R. Kaushik, R. Kumria, A. Trehan, Poly- $\varepsilon$-caprolactone microspheres and nanospheres: an overview, International Journal of Pharmaceutics 278 (2004) 1-23

[35] Ricci, G., Patrizi, A., Bellini GF., Medri, M. Use of Textiles in Atopic Dermatitis in Burg G (ed): Biofunctional Textiles and Skin, Curr Probl Dermatol. Basel, Karger, 2006, vol 33, 127-143. 